\title{
Effectiveness of interdisciplinary primary care approach to reduce disability in community dwelling frail older people: cluster randomised controlled trial
}

\author{
(c) $\frac{(1)(8)}{\text { gy }}$ OPEN ACCESS
}

\author{
Silke F Metzelthin scientific researcher ${ }^{1}$, Erik van Rossum lecturer in innovations in care for frail \\ elderly $^{2}$, Luc P de Witte professor of technology in care ${ }^{3}$, Antonius W Ambergen statistician ${ }^{4}$, Sjoerd \\ O Hobma general practitioner ${ }^{5}$, Walther Sipers geriatrician ${ }^{6}$, Gertrudis I J M Kempen professor of \\ social gerontology ${ }^{1}$
}

\begin{abstract}
${ }^{1}$ Department of Health Services Research - Focusing on Chronic Care and Ageing, CAPHRI School for Public Health and Primary Care, Maastricht University, P O Box 616, 6200 MD Maastricht, Netherlands; ${ }^{2}$ Centre of Research on Autonomy and Participation, Zuyd University of Applied Sciences, P O Box 550, 6400 AN Heerlen, Netherlands ; ${ }^{3}$ Centre of Research on Technology in Care, Zuyd University of Applied Sciences ; ${ }^{4}$ Department of Methodology and Statistics, CAPHRI School for Public Health and Primary Care, Maastricht University ; ${ }^{5}$ Department of General Practice, CAPHRI School for Public Health and Primary Care, Maastricht University ; ${ }^{6}$ Orbis Medical Centre, P O Box 5500, 6130 MB Sittard, Netherlands
\end{abstract}

\begin{abstract}
Objective To evaluate whether an interdisciplinary primary care approach for community dwelling frail older people is more effective than usual care in reducing disability and preventing (further) functional decline.

Design Cluster randomised controlled trial.

Setting 12 general practices in the south of the Netherlands

Participants 346 frail older people (score $\geq 5$ on Groningen Frailty Indicator) were included; 270 (78\%) completed the study.

Interventions General practices were randomised to the intervention or control group. Practices in the control group delivered care as usual. Practices in the intervention group implemented the "Prevention of Care" (PoC) approach, in which frail older people received a multidimensional assessment and interdisciplinary care based on a tailor made treatment plan and regular evaluation and follow-up.

Main outcome measures The primary outcome was disability, assessed at 24 months by means of the Groningen Activity Restriction Scale. Secondary outcomes were depressive symptomatology, social support interactions, fear of falling, and social participation. Outcomes were measured at baseline and at 6,12 , and 24 months' follow-up.

Results 193 older people in the intervention group (six practices) received the $\mathrm{PoC}$ approach; 153 older people in the control group (six practices) received care as usual. Follow-up rates for patients were $91 \%$ $(n=316)$ at six months, 86\% $(n=298)$ at 12 months, and $78 \%(n=270)$ at 24 months. Mixed model multilevel analyses showed no significant differences between the two groups with regard to disability (primary outcome) and secondary outcomes. Pre-planned subgroup analyses confirmed these results.
\end{abstract}

Conclusions This study found no evidence for the effectiveness of the PoC approach. The study contributes to the emerging body of evidence that community based care in frail older people is a challenging task. More research in this field is needed.

Trial registration Current Controlled Trials ISRCTN31954692.

\section{Introduction}

In our ageing society, care for older people is one of the greatest challenges in healthcare. ${ }^{12}$ Evidence suggests that community based care in comparison with institutionalisation may achieve better outcomes at lower costs and is preferred by older people themselves. ${ }^{3}$ Consequently, an increasing demand exists for innovative initiatives to provide cost effective community based care. ${ }^{5}$ In most Western countries, such as the United Kingdom and the Netherlands, general practitioners have a central position in the provision of community care, as they are gatekeepers to specialised and hospital care. ${ }^{7}$ In the UK, general practitioners have been required since 1990 to offer an annual

multidimensional assessment to their patients aged 75 years and over. ${ }^{8}$ In addition, general practitioners' geographical proximity to older people and their intense and long lasting relationship with their patients may contribute to effective care in older people. ${ }^{7}$ However, community based care of frail older people is challenging. Frail older people have multiple and complex healthcare needs, which often lead to disability. ${ }^{9-11}$ Disability is defined as difficulty or dependency in the execution of daily activities that are essential for independent living. ${ }^{9}$ As disability is considered a dynamic process, older people can recover to a 
less disabled or non-disabled state. ${ }^{12}$ Regardless, preventive actions have to be taken to improve the abilities of frail older people to remain at home as long as possible. ${ }^{13}$

Daniëls and colleagues did a narrative review to provide an extensive overview of existing interventions for prevention of disability in community dwelling frail older people. ${ }^{14}$ The identified interventions, most of which were in the field of comprehensive geriatric assessment and physical exercise programmes, showed a large diversity in terms of content, disciplines involved, duration, intensity, and setting. Only a small number have shown beneficial effects with regard to disability, and most studies did not report on any long term effects. ${ }^{14}$ On the basis of this review, the authors suggested that community care interventions for frail older people should be conducted by an interdisciplinary primary care team involving individualised assessments and interventions (tailor made care), self management support, engagement in meaningful activities, case management, and long term follow-up. In an effort to reduce disability and prevent (further) functional decline in community dwelling frail older people, we have combined these elements into one approach: the "Prevention of Care" (PoC) approach. This approach focuses on both older people with an increased risk for developing disability and older people who are already disabled. ${ }^{15}$ A previous pilot study $(n=41)$ using the PoC approach has shown promising results. ${ }^{15}$ Older people appreciated the attention they got and felt supported in reaching their goals and in handling future disability. Healthcare professionals reported that the approach provided a useful structure for geriatric primary care. In addition, the approach stimulated interdisciplinary collaboration, a focus on meaningful activities, and self management support. ${ }^{15}$ However, the effectiveness with regard to disability and various related outcomes has not yet been studied. Consequently, we conducted this trial to investigate the effectiveness of the PoC approach on various patient level outcomes compared with usual care. ${ }^{16}$ We chose a cluster randomised design for practical reasons and to avoid contamination bias. ${ }^{17}$

\section{Methods}

\section{Study design}

We did a two arm cluster randomised controlled trial among 12 general practices in the south of the Netherlands. Before the screening procedure for identifying frail older people started, we randomly allocated six practices to the PoC approach and six practices to continue care as usual. Before randomisation, the practices were pre-stratified into four strata based on number of older patients ( $<350$ versus $\geq 350$ patients) and location (urban versus rural area). We assumed that general practitioners working in a practice with a large number of older patients have more experience with geriatric care and that older people living in a rural area receive more support from the informal care system than do those living in an urban area. We stratified the practices in pairs and used a computer generated randomisation list to randomise them into either the intervention or control group. To promote extrapolation of the results, practices in an urban area with a large number of older people had twice the chance of being allocated to the intervention group than did practices in the other three strata. The cluster randomised controlled trial was performed as planned. More details of the study design have been published elsewhere. ${ }^{16}$

\section{Participants}

We invited all general practices in the region of Sittard (the Netherlands) and its surrounding area that had no current active and systematic policy for the detection and follow-up of frail older people to take part in the study. In total, 24 practices were interested, of which we randomly selected 12 for the study on the basis of a computer generated list of numbers. The study focuses on their community dwelling frail older patients $(\geq 70$ years). Those who were terminally ill, were confined to bed, had severe cognitive or psychological impairments, or were unable to communicate in Dutch were excluded on the basis of the advice of the general practitioner. The remaining other older people $(n=3498)$ in the 12 practices received a postal questionnaire, including the Groningen Frailty Indicator. ${ }^{18}$ In the literature, a score of 4 or higher (range 0-15) is proposed as the cut-off point for moderately to severely frail older people. ${ }^{18}$ However, this study focused on people who were considerably frail, ranging from people who have an increased risk for developing disability to disabled older people. Therefore, older people who signed the informed consent form and had a Groningen Frailty Indicator score of 5 or higher were included in the study. For practical reasons, the recruitment of frail older people took place in three cycles. The first cycle started in December 2009, the second in February 2010, and the third in March 2010. The intervention and the collection of data also took place in three cycles. All included older people gave written informed consent before collection of the baseline measure.

\section{Intervention}

In the intervention group (six practices), frail older people received the PoC approach. The general practitioner and practice nurse built the core team of the interdisciplinary care approach. In 2001 the profession of practice nurse was introduced in the Netherlands to reduce the workload of Dutch general practitioners, who are the gatekeeper to specialised and hospital care. ${ }^{19}$ Practice nurses often work, under the supervision of the general practitioner, on disease prevention, chronic care management, mental health services, assessments of frail older people, and care of families with young children. ${ }^{20}$ Within the PoC approach, the general practitioner and practice nurse cooperate closely with occupational and physical therapists. If needed, other inpatient and outpatient healthcare professionals, such as a pharmacist or a geriatrician, are involved as well.

The PoC approach aims to reduce disability and prevent (further) functional decline by using a six step approach (fig $1 \Downarrow$ ). ${ }^{21}$ After the postal screening for frailty using the Groningen Frailty Indicator (step 1), frail older people and their informal caregiver, if available, receive a home visit by the practice nurse who does a multidimensional assessment focusing on existing problems in performing daily activities and on risk factors for disability (step 2). The focus is on activities that are meaningful to the older person. Examples of meaningful activities are gardening, visiting family/friends, reading a book, taking a walk, playing games, and joining religious activities. After the home visit, the general practitioner and practice nurse discuss whether additional assessments by other inpatient or outpatient healthcare professionals are needed. On the basis of the assessment phase, a preliminary treatment plan is formulated (step 3), either in a bilateral meeting (general practitioner and practice nurse) or in an extended team meeting consisting of a general practitioner, practice nurse, occupational and physical therapist, and, if necessary, other healthcare professionals.

During a second home visit by the practice nurse (step 4), a final treatment plan is formulated, including a list of goals, strategies, and actions that meet the older person's needs. Depending on the self management skills and preferences of the older person, strategies and actions are either focused on the older person or more on (support of) the social and physical environment. On 
the basis of the 5As Behavioural Change Model, ${ }^{22}$ and motivational interviewing techniques, ${ }^{23}$ the practice nurse encourages active involvement in decision making and establishes a cooperative working relationship with the frail older person and the informal caregiver. Subsequently, the treatment starts (step 5). The intervention protocol offers recommendations and guidelines for the execution of the treatment plan. For example, a toolbox of interventions is available that focuses on five topics: "enhancing meaningful activities," "daily physical activity," "social network and social activities," "adapting the environment, activities, or skills," and "stimulating health." The practice nurse is also the case manager and, along with the frail older person and the informal caregiver, regularly evaluates the achievement of goals, the implementation of strategies in daily life, and the need for support in the following period (step 6). The professionals involved are updated about the progress and the agreements made. The box illustrates how the approach works.

The remaining six practices (control group) continued to deliver care as usual.

\section{Measurements}

We measured data for the effectiveness analysis at the level of the patient at baseline and after 6,12 , and 24 months by using postal questionnaires and telephone interviews. Whereas older people and healthcare professionals were aware of the allocated arm (intervention or control), outcome assessors were kept blinded to the allocation.

\section{Outcome measures}

We measured the primary outcome, disability, at 24 months by means of the Groningen Activity Restriction Scale. ${ }^{24}$ This is an easy to administer, comprehensive, reliable, hierarchical, and valid measure for assessing disability in older people. It consists of two subscales. The first subscale is about activities of daily living (11 items), and the second subscale relates to instrumental activities of daily living (seven items). The scores for the total scale range from 18 to 72 , with higher scores indicating more disability. ${ }^{24}$ As disability is strongly related to psychological and social functioning, ${ }^{25}$ we chose depressive symptomatology (depression subscale of the Hospital Anxiety and Depression Scale), ${ }^{26}$ social support interactions (Social Support List-Interaction version), ${ }^{27}$ fear of falling (Short Falls Efficacy Scale-International), ${ }^{28}$ and social participation (Maastricht Social Participation Profile, subscale A $)^{29}$ as secondary outcomes. In addition, we used the Pearlin Mastery Scale to determine the feelings of competence and control in older people ${ }^{30}$ feelings crucial for self management and coping, ${ }^{31}$ which belong to the important underlying mechanisms of the PoC approach.

\section{Statistical analysis}

We used descriptive techniques to describe the study groups. We compared baseline variables to detect differences between the intervention and control groups at the start of the study. Because of the cluster randomised design of the study including three levels (general practices, participants, and repeated measurements), we applied a mixed model multilevel analysis. We analysed the primary and secondary outcomes, measured at the level of the patient, according to the intention to treat principle. We imputed missing values at the level of the scale by means of multiple imputations. We based the maximum number of missing values within a scale on the guidelines given by the developers. If no guidelines were available, we accepted a limit of $25 \%$ missing values. Multilevel analyses are quite robust against missing values at the measurement level. Therefore, we needed at least the baseline measurement and one out of three follow-up measurements to include older people in the analyses. For all analyses, we used a standard model including six independent variables. We corrected outcome estimates of the multilevel analyses for age, sex, educational level, significant differences at baseline (frailty and disability), and the baseline status of the outcome variable (in the case of secondary outcomes) by including these variables as covariates in each model. We obtained insight into the effectiveness of the PoC approach in comparison with usual care at various follow-up times by examining fixed effects for group by time interaction. We evaluated the trend in time by removing the interaction term (group by time) from the model and testing only fixed effects for group and time. In a few imputed datasets, variance of practice iterated to zero. Consequently, we examined in a basic model of disability, including only baseline status of disability as a covariate, whether practice had an effect on outcomes. The analyses of the basic model with and without practice as a random effect showed that the results were highly similar for the two analyses. Therefore, we decided to exclude practice as an extra level.

We did several subgroup analyses. Firstly, we divided older people in the intervention group into two subgroups on the basis of their exposure to the PoC approach. We compared older people who received only assessment(s) (exposure group low) with those who received interventions, follow-up visits, or both (exposure group high). We tested fixed effects for exposure group by time interactions for significance. In addition, we did pre-planned subgroup analyses for the potential effect modifiers baseline status of frailty and mastery. ${ }^{16} \mathrm{We}$ created two groups for each effect modifier based on the median scores: low frailty (Groningen Frailty Indicator score 5-6) versus high frailty (score 7-14) and low mastery (Pearlin Mastery Scale score 23-32) versus high mastery (score 10-22). Again, we tested fixed effects for effect modifier by group interactions for significance.

The sample size calculation was based on our primary outcome (disability). On the basis of a power of $80 \%$ and an $\alpha$ of 0.05 (two tailed testing), and an expected treatment difference of at least 2.0 points on the Groningen Activity Restriction Scale, ${ }^{24}$ the required sample size was 80 per group (160 in total). Accounting for a dropout rate of $30 \%$ and a cluster effect of 1.73 (intraclass correlation coefficient 0.05 ), ${ }^{16}$ assuming equal cluster sizes, the final sample size had to be 180 per group (360 in total). ${ }^{16}$ We used the software package SPSS for Windows, version 20.0 , for all statistical analyses.

\section{Results}

We allocated 12 general practices at random to the control (six practices) or intervention group (six practices). Half of the practices had less than 350 patients and half had at least 350 patients. In addition, six practices were located in an urban area and six in a rural area. These cluster characteristics were equally distributed among the groups. As shown in figure $2 \Downarrow, 3498$ community dwelling older patients ( $\geq 70$ years) of the 12 practices received the screening questionnaire. The response rate was $80 \%(n=2790)$. Non-responders were significantly younger than responders (mean age $76.75 v 77.62$ years; $\mathrm{P}<0.05)$, and slightly more non-responders were men (42.9\% v $39.1 \% ; \mathrm{P}=0.07$ ). Older people who completed the questionnaire and were willing to participate in the study $(n=1101)$ were significantly frailer than respondents who completed the questionnaire but declined participation $(n=1634)$ (mean score 


\begin{abstract}
Case summary
AK is a 75 year old woman living independently in a small flat. She has four children, who live in the same city. Her husband has been living in a nursing home for two years.

AK received a letter from her general practitioner, who asked her to fill in the Groningen Frailty Indicator (step 1). She had a total frailty score of 7 , and the practice nurse called her to offer a home visit for a multidimensional assessment (step 2). The assessment focused on existing problems in performing daily activities and risk factors for developing disability. The practice nurse also discussed with AK her individual needs and goals and her motivation to make changes in her life. AK's most important goal was to stay independently in her home. She experienced problems with cooking, shopping, and visiting her husband in the nursing home. The last of these was particularly meaningfu to her. She often felt exhausted and had a fear of falling. In addition, memory deficits affected her participation in daily life. Her chronic diseases (diabetes and heart failure) were under control.

After the home visit, the practice nurse discussed the results of the assessment with the general practitioner and decided to refer AK to a geriatrician for further cognitive assessment. In addition, they agreed that involving an occupational therapist and physiotherapist would also be useful, as AK had problems with daily activities. An interdisciplinary team meeting, consisting of the general practitioner, practice nurse, occupational therapist, and physiotherapist took place to formulate a preliminary treatment plan based on the results of the assessment (step 3). The assessment of the geriatrician showed no signs of dementia. Regarding her fear of falling, the team assumed that AK needed to change her attitudes and self efficacy beliefs with regard to falling, leading towards improved participation in daily activities such as shopping and visiting her husband. An increase in physical activity was supposed to positively affect her fear of falling as well. In addition, simple strategies and a few helping aids were discussed to help AK with cooking and handling her memory deficits.

After the team meeting, the practice nurse visited AK again to finalise the treatment plan (step 4). Which toolbox parts could be used was also discussed. For the treatment of AK the toolboxes "adapting the environment, activities, or skills" and "daily physical activity" were chosen (step 5). During the treatment, the practice nurse visited AK four times to evaluate the achievement of goals and the implementation of strategies in daily life (step 6). Four months later, during the last visit, AK reported that she had fewer problems with cooking and visiting her husband. She had increased her physical activity in daily life and had less fear of falling. However, the strategies learnt for handling her memory deficits were still difficult to apply in daily life. A few helping aids and a stool placed in the kitchen helped her to cook more efficiently. The practice nurse will visit AK every six months to follow-up with her.
\end{abstract}

on Groningen Frailty Indicator 3.64 v 2.96 ; $\mathrm{P}<0.05)$. Several participants declined participation and the questionnaire was not (completely) filled in ( $\mathrm{n}=55)$, so we were not able to obtain frailty scores and have no information about the level of frailty. Of the older people who were willing to participate, $34 \%$ $(n=179)$ in the control group and $38 \%(n=214)$ in the intervention group were frail according to their frailty score (score $\geq 5$ ). Of the 393 older people who were eligible for the study (were frail and gave written informed consent), 47 were not included in the study, as they had not completed the baseline measurement (fig $2 \Downarrow$ ). Finally, 346 older people were included in the study, 193 (56\%) of whom received the PoC approach. The mean age of participants was 77.2 (SD 5.1) years, 58\% $(\mathrm{n}=199)$ were female, $49 \%(\mathrm{n}=170)$ were living alone, and $58 \%$ $(n=202)$ had a low level of education.

We found significant differences between intervention and control group participants with regard to frailty (Groningen Frailty Indicator) and disability (Groningen Activity Restriction Scale) scores. The intervention group participants were significantly frailer (score $7.13 v 6.72 ; \mathrm{P}<0.05$ ) and more disabled (score $33.09 v 30.58 ; \mathrm{P}<0.05$ ). All other characteristics were similar between the groups at baseline (table $1 \Downarrow$ ). In total, 76 older people were lost to follow-up during the trial, significantly more of them in the intervention group $(26 \% \mathrm{v}$ $17 \%$; $\mathrm{P}<0.05)$.

\section{Primary outcome}

All 12 clusters, consisting of 310 frail older people with a baseline disability score and at least one out of three follow-up measurements, were included in the mixed model multilevel analyses. With regard to disability, we identified no significant difference between the control and intervention groups at 24 months' follow-up. We found no significant group by time interaction effects for the total Groningen Activity Restriction Scale scores or for the activities of daily living and instrumental activities of daily living subscale scores. After removing the interaction term from the model, we tested the trend for time. Both groups increased significantly $(\mathrm{P}<0.05)$ in disability over a period of 24 months, but no significant differences between the groups with respect to their increase existed. Table $2 \Downarrow$ gives a summary of these results.

\section{Secondary outcomes}

Table $3 \Downarrow$ shows the results of the secondary outcomes. Again, we found no significant group by time interaction effects of the intervention group on any of these outcomes.

\section{Subgroup analyses}

The fixed effects for exposure groups (low versus high) by time interactions were not significant $(\mathrm{P}>0.05)$. We found no significant $(\mathrm{P}>0.05)$ mediating effects for a higher level of mastery or a lower level of frailty (data not shown).

\section{Discussion}

Our study has provided no evidence for the effectiveness of a proactive primary care approach, consisting of a multidimensional assessment with interdisciplinary care based on a tailor made treatment plan and regular evaluation and follow-up, among frail older people. We found no significant differences between the intervention group and the control group (care as usual) with regard to disability (primary outcome) or our secondary outcomes: depressive symptomatology, social support interactions, fear of falling, and social participation. Pre-planned subgroup analyses confirmed these results.

\section{Strengths and weaknesses of study}

The strengths of this cluster randomised trial include a long follow-up period with relatively few missing data and high follow-up rates. In addition, we used outcome measures with good psychometric properties, which were assessed by blinded data collectors. This study also has some weaknesses. Firstly, significant baseline differences existed between the intervention and control groups with regard to frailty and disability, and the sample size distribution was skewed. These differences were a result of the cluster randomised design of the study, which is a common approach with this kind of intervention to avoid contamination bias. ${ }^{17}$ Although we adjusted for baseline differences in our analyses, this may still have affected our findings to some extent. Secondly, significantly more participants were lost to follow-up in the intervention group than in the control group ( $26 \% v 17 \%$ ). We cannot fully explain this finding, but older people in the intervention group were significantly more frail and disabled than those in the control group, which might have affected the completion rate. Thirdly, 
the PoC approach was evaluated in a real life setting in 12 general practices. Although we did a comprehensive process evaluation alongside the trial, ${ }^{32}$ we have limited insight into what happened in practice for several reasons. Participating older people were patients of their general practitioner irrespective of their study participation. Consequently, making a distinction between usual care activities and contacts related to the PoC approach was difficult, resulting in an overlap in time spent in delivering usual care versus the new approach. Also, practice nurses had trouble in determining a clear endpoint of the PoC approach, because older people remained patients of their general practitioners after the PoC approach had been delivered, resulting in continuous monitoring of older people. In addition, older people were referred to other healthcare professionals as well. As a result, we do not know exactly how much time was spent in delivering the PoC approach and how for long these activities were continued. However, the process evaluation showed that slightly more than one third of the participants in the intervention group (34\%) had only the multidimensional assessment conducted by the practice nurse during an initial home visit. The remaining older people received a tailor made treatment followed by up to five follow-up visits by the practice nurse.

\section{Comparison with other studies}

During the past decades, much research targeting community dwelling (frail) older people has been done, with many studies in the field of preventive home visiting programmes. Since 2000, several meta-analyses, systematic reviews, and literature reviews have been published. ${ }^{12}{ }^{13} 33-37$ The studies evaluated a range of interventions (such as multidimensional geriatric assessment, care planning, organisation and monitoring, health promotion, self management support, nursing services, and referrals to other services) carried out by various professionals (general practitioners, nurses, allied professionals). The aim of these interventions is to proactively detect modifiable risk factors and worsening health conditions to reduce or prevent disability, healthcare use, and related costs. Results regarding the effectiveness of these interventions have been inconsistent and conflicting. A few studies have shown favourable effects on disability. For example, Bernabei and colleagues did a randomised controlled trial showing that a model of integrated care and case management had favourable effects on disability in community dwelling older people. ${ }^{38}$ Services were provided by the general practitioner and a community geriatric evaluation unit, consisting of a geriatrician, a social worker, and several nurses. Gill and colleagues have reported a successful randomised controlled trial evaluating an intense exercise programme for physically frail older people living in the community. ${ }^{39}$ The programme is based on the outcomes of an extensive assessment; it focuses on the individual needs of older people but also takes their environmental conditions into account. Most studies, however, reported no or only modest effects of their interventions. Also, the largest trial in this field, by Fletcher and colleagues, comparing different strategies for assessment (targeted versus universal) and evaluation and management (primary care versus multidisciplinary geriatric team) in more than 40000 older people, did not result in convincing effects or adequate evidence that one strategy is better than another. ${ }^{40}$

\section{Meaning of study: explanations and clinical implications}

Besides the methodological drawbacks, some other explanations for the lack of effects are possible. These relate to the target group, insufficient implementation of the PoC approach, and current healthcare delivery in the Netherlands.

Firstly, the PoC approach focuses on frail older people (Groningen Frailty Indicator score $\geq 5$ ). The baseline disability score in our frail sample (mean 32.0, SD 11.2) was substantially higher than that in a comparable sample ( $\geq 70$ years) of the Dutch general population (mean 24.9, SD 9.3). ${ }^{41}$ Some of the participants in our study may have been too frail, as some previous reviews in the field of preventive home visiting programmes suggest that interventions may be more effective in low risk, non-disabled older people. ${ }^{25} 33$ This is in line with a more recent review reporting that frail older people have to be identified at a relatively early stage when negative health outcomes can still be avoided. ${ }^{42}$ In contrast, practice nurses and general practitioners interviewed during the process evaluation mentioned that a large number of participants were in their view not eligible for the PoC approach, as they had hardly any disability in terms of activities of daily living and instrumental activities of daily living. ${ }^{32}$ In efforts to reduce disability and prevent (further) functional decline, which older people would benefit the most from interventions such as the PoC approach is still not clear.

Secondly, the process evaluation showed that some parts of the intervention protocol were not implemented as planned. ${ }^{32}$ The problem analysis and the development of a preliminary treatment plan (step 3) was often not done in a bilateral meeting or an extended team meeting, and only half of the treatment plans were discussed with the frail older person (step 4). Also, the toolbox parts were not frequently used in the treatment phase (step 5), and the extent of evaluation and follow-up, especially among the healthcare professionals, was limited (step 6). ${ }^{32}$ Insufficient implementation is a well known problem, especially in the field of preventive and behavioural change interventions. ${ }^{43}$ During the process evaluation, professionals mentioned that some parts of the intervention protocol were (too) time consuming or difficult to apply ${ }^{32}$; this may have been a reason for insufficient implementation. ${ }^{43}$ In addition, professionals expressed a need for more training on the job and more opportunities to exchange experiences with each other. Education and experience of professionals and the intensity of provided training activities are strongly related to beneficial outcomes. ${ }^{12}$ Despite an extensive development period and a comprehensive training programme with regard to the intervention protocol, we probably failed in providing professionals with the necessary competencies and feasible tools to apply rather complex concepts, such as interdisciplinary collaboration, tailor made care, and self management support, into daily practice. ${ }^{32}$ For example, the development of individualised goals, a prerequisite for tailor made care and self management support, is a challenging task, as patients tend to adopt a passive role in goal setting. ${ }^{44}$ Encouragement of active involvement is even more difficult with older people owing to highly prevalent cognitive impairments, communication difficulties, and comorbidities and as such requires a unique set of competencies. ${ }^{45}$ Goal identification tools, such as the Canadian Occupational Performance Measure or Goal Attainment Scaling, ${ }^{46}$ may be useful in the process of goal setting. In addition, more attention has to be paid to the implementation of evaluation and follow-up activities, as a minimum intensity and length of follow-up is needed to reach favourable effects. ${ }^{25} 34$

Thirdly, standard healthcare delivery in the Netherlands is already at a relatively high level. Nearly all people are covered by healthcare insurance, healthcare is easily accessible, and its quality is often considered to be good. ${ }^{48}$ Moreover, the contrast 
between the PoC approach and care as usual was probably too small to detect substantial effects. The non-effective results of this study and the complexity of effective interventions (or elements) described in the literature mean that drawing conclusions about which specific strategies would result in a surplus effect in which target group is difficult.

\section{Future research}

Although this study has not shown any beneficial effects of a proactive primary care approach, including a multidimensional assessment and interdisciplinary care based on a tailor made treatment plan and regular evaluation and follow-up, in frail older people, it adds to the evidence base for clinical decision making and future research regarding community based care for such people. The publication of non-effective studies is highly relevant to prevent an overestimation of the benefits of interventions and a waste of healthcare resources. This study contributes to the emerging body of evidence that more research is needed to improve the effectiveness of interventions for frail older people.

We thank the participants in the study; the participating healthcare professionals; the Centre for Data and Information Management (MEMIC): Anita Legtenberg, Alfons Schroten, and Marlène Ronner; the members of the research group: Lilo Crasborn (MCC Omnes), Simone Denis (MCC Omnes), Marlou Wolters (MCC Omnes), Herbert Habets (Orbis Medical Centre), and Ramon Daniels (Zuyd University of Applied Sciences, Heerlen); their research assistants: Floor Koomen, Ine Hesdahl, and Astrid Dello; and their sponsors: the Netherlands Organisation for Health Research and Development (ZonMw), the Hague, the Netherlands, and the Netherlands Organisation for Scientific Research (NWO), the Hague, the Netherlands.

Contributors: SFM, EvR, LPdW, and GIJMK were responsible for the conception and design of the study. SFM, EvR, LPdW, AWA, SOH, WS, and GIJMK were involved in the analysis and interpretation of the data. SFM created the first draft of this paper. The other authors commented on it and approved the final version. All authors had full access to all of the data and can take responsibility for the integrity of the data and the accuracy of the data analysis. SFM is the guarantor.

Funding: This research is funded by the Dutch National Care for the Elderly Programme by The Netherlands Organisation for Health Research and Development (ZonMw 311070301). It is an initiative of the Dutch Ministry of Health, Welfare and Sport to improve the quality of care for frail older people (www.nationaalprogrammaouderenzorg. nl). Open access of this publication was financed by the Netherlands Organisation for Scientific Research (NWO).

Competing interests: All authors have completed the ICMJE uniform disclosure form at www.icmje.org/coi_disclosure.pdf (available on request from the corresponding author) and declare: this research is funded by the Dutch National Care for the Elderly Programme by The Netherlands Organisation for Health Research and Development; no financial relationships with any organisations that might have an interest in the submitted work in the previous three years; no other relationships or activities that could appear to have influenced the submitted work. Ethical approval: The study was approved by the Medical Ethical Committee of the Maastricht University/Academic Hospital Maastricht in the Netherlands in 2009 (MEC 09-3-067). Between randomisation and baseline measurement, all included participants gave written informed consent.

Data sharing: Additional data from the study database are available on request from the corresponding author at

s.metzelthin@maastrichtuniversity.nl. Data will be provided at group level, as participants' consent to share their data was not obtained.
1 Bergman $\mathrm{H}$, Béland F, Perrault A. The global challenge of understanding and meeting the needs of the frail older population. Aging Clin Exp Res 2002:14:223-5.

2 Coleman EA. Challenges of systems of care for frail older persons: the United States of America experience. Aging Clin Exp Res 2002;14:233-8.

3 Woolhandler S, Campbell T, Himmelstein DU. Costs of health care administration in the United States and Canada. N Engl J Med 2003;349:768-75.

4 Ploeg J, Brazil K, Hutchison B, Kaczorowski J, Dalby DM, Goldsmith CH, et al. Effect of preventive primary care outreach on health related quality of life among older adults at risk of functional decline: randomised controlled trial. BMJ 2010;340:c1480.

5 Keating N, Ottinowski P, Wenger C, Fast J, Derksen L. Understanding the caring capacity of informal networks of frail seniors: a case for care networks. Ageing Soc 2003;23:115-27.

6 Markle-Reid M, Browne G, Weir R, Gafni A, Roberts J, Henderson SR. The effectiveness and efficiency of home-based nursing health promotion for older people: review of the literature. Med Care Res Rev 2006;63:531-69.

7 Stijnen MMN, Duimel-Peeters IGP, Jansen MWJ, Vrijhoef HJM. Early detection of health problems in potentially frail community-dwelling older people by general practices-project [G]OLD: design of a longitudinal, quasi-experimental study. BMC Geriatr 2013;13(7):1-10.

8 Fletcher AE, Jones DA, Bulpitt CJ, Tulloch AJ. The MRC trial of assessment and management of older people in the community: objectives, design and interventions [ISRCTN23494848]. BMC Health Serv Res 2002;2(1):21.

9 Fried LP, Ferrucci L, Darer J, Williamson JD, Anderson G. Untangling the concepts of disability, frailty, and comorbidity: implications for improved targeting and care. Gerontol A Biol Sci Med Sci 2004;59:255-63.

10 Markle-Reid M, Browne G. Conceptualizations of frailty in relation to older adults. $J$ Adv Nurs 2003;44:58-68.

11 Pel Littel RE, Schuurmans MJ, Emmelot Vonk MH, Verhaar HJJ. Frailty: defining and measuring of a concept. J Nutr Health Aging 2009;13:390-4.

12 Liebel DV, Friedman B, Watson NM, Powers BA. Review of nurse home visiting interventions for community-dwelling older persons with existing disability. Med Care Res Rev 2009;66:119-46.

13 Hallberg IR, Kristensson J. Preventive home care of frail older people: a review of recent case management studies. J Clin Nurs 2004;13(6B):112-20.

14 Daniels R, Metzelthin S, Van Rossum E, De Witte L, Van den Heuvel W. Interventions to prevent disability in frail community-dwelling older persons: an overview. Eur J Ageing 2010;7:37-55

15 Daniels R, van Rossum E, Metzelthin S, Sipers W, Habets H, Hobma S, et al. A disability prevention programme for community-dwelling frail older persons. Clin Rehabil 2011;25:963-74.

16 Metzelthin SF, van Rossum E, de Witte LP, Hendriks MR, Kempen GI. The reduction of disability in community-dwelling frail older people: design of a two-arm cluster randomized controlled trial. BMC Public Health 2010;10:511

17 Campbell MK, Elbourne DR, Altman DG, CONSORT Group. CONSORT statement: extension to cluster randomised trials. BMJ 2004;328:702-8.

18 Steverink N, Slaets JPJ, Schuurmans $\mathrm{H}$, van Lis M. Measuring frailty: development and testing of the Groningen Frailty Indicator (GFI). The Gerontologist 2001;41(1):236-37.

19 Derckx E. Eerste nurse practitioners met differentiatie huisartsenzorg. Tijdschrift voor Verpleegkundigen 2006;3:26-30

20 Van Weel C, Schers H, Timmermans A. Health care in the Netherlands. J Am Board Fam Med 2012;25(suppl 1):S12-7.

21 Daniels $\mathrm{R}$. Frail elderly-identification and disability prevention in primary care $[\mathrm{PhD}$ Thesis]. Maastricht University, 2011.

22 Glasgow RE, Emont S, Miller DC. Assessing delivery of the five 'As' for patient-centred counseling. Health Promot Int 2006;21:245-55

23 Miller WR, Rollnik S. Motivational interviewing: preparing people for change. Guildford Publications, 2002.

24 Kempen GIJM, Miedema I, Ormel J, Molenaar W. The assessment of disability with the Groningen Activity Restriction Scale: conceptual framework and psychometric properties. Soc Sci Med 1996:43:1601-10.

25 Stuck AE, Walthert JM, Nikolaus T, Bula CJ, Hohmann C, Beck JC. Risk factors for functional status decline in community-living elderly people: a systematic literature review. Soc Sci Med 1999;48:445-69.

26 Spinhoven P, Ormel J, Sloekers PPA, Kempen GlJM, Speckens AEM, van Hemert AM A validation study of the Hospital Anxiety and Depression Scale (HADS) in different groups of Dutch subjects. Psychol Med 1997;27:363-70.

27 Kempen GIJM, van Eijk LM. The psychometric properties of the SSL12-I, a short scale for measuring social support in the elderly. Soc Indic Res 1995;35:303-12.

28 Kempen GIJM, Yardley L, van Haastregt JCM, Zijlstra GAR, Beyer N, Hauer K, et al. The Short FES-I: a shortened version of the falls efficacy scale-international to assess fear of falling. Age Ageing 2008;37:45-50.

29 Mars GMJ, Kempen GIJM, Post MWM, Proot IM, Mesters I, van Eijk JTM. The Maastricht social participation profile: development and clinimetric properties in older adults with a chronic physical illness. Qual Life Res 2009;18:1207-18.

30 Pearlin LI, Schooler C. The structure of coping. J Health Soc Behav 1978;19:2-21.

31 Kempen GIJM. Preventie en ouder worden: mogelijkheden voor zelfmanagement. Epidemiologisch bulletin 2006;41(2):27-32.

32 Metzelthin SF, Daniels R, Van Rossum E, Cox K, Habets H, de Witte LP, et al. A nurse-led interdisciplinary care approach to prevent disability among community-dwelling frail older people: a large-scale process evaluation. Int J Nurs Stud 2013;50:1184-96.

33 Elkan R, Kendrick D, Dewey M, Hewitt M, Robinson J, Blair M, et al. Effectiveness of home based support for older people: systematic review and meta-analysis. BMJ 2001;323:719-25.

34 Stuck AE, Egger M, Hammer A, Minder CE, Beck JC. Home visits to prevent nursing home admission and functional decline in elderly people: systematic review and meta-regression analysis. JAMA 2002;287:1022-8.

35 Bouman A, van Rossum E, Nelemans P, Kempen GIJM, Knipschild P. Effects of intensive home visiting programs for older people with poor health status: a systematic review. BMC Health Serv Res 2008:8:74.

36 Huss A, Stuck AE, Rubenstein LZ, Egger M, Clough-Gorr KM. Multidimensional preventive home visit programs for community-dwelling older adults: a systematic review and meta analysis of randomized controlled trials. J Gerontol A Biol Sci Med Sci 2008;63:298-307.

37 Van Haastregt JC, Diederiks JP, van Rossum E, de Witte LP, Crebolder HF. Effects of preventive home visits to elderly people living in the community: systematic review. $B M J$ 2000;320:754-8. 


\section{What is already known on this topic}

Compared with institutionalisation, community based care of older people may achieve better outcomes at lower costs and is also preferred by older people themselves

Various community based interventions aiming at reduction of disability have been developed during the past decades

However, only a small number of interventions have shown beneficial effects on disability, and most studies did not report on the long term effects

\section{What this study adds}

No evidence was found for the effectiveness of a proactive primary care approach, including a multidimensional assessment, interdisciplinary care based on a tailor made treatment plan, and regular evaluation and follow-up, in frail older people

Effective education and training programmes are needed to provide healthcare professionals with adequate competencies and feasible tools to face the challenges of community based care in frail older people

The non-effective results of this study mean that more research is needed to optimise the effectiveness of community based interventions for frail older people

38 Bernabei R, Landi F, Gambassi G, Sgadari A, Zuccala G, Mor V, et al. Randomised trial of impact of model of integrated care and case management for older people living in the community. BMJ 1998;316:1348-51.

39 Gill TM, Baker DI, Gottschalk M, Peduzzi PN, Allore H, Byers A. A program to prevent functional decline in physically frail, elderly persons who live at home. $N$ Engl $J$ Med 2002;347:1068-74.

40 Fletcher AE, Price GM, Ng ESW, Stirling SL, Bulpitt CJ, Breeze E, et al. Population-based multidimensional assessment of older people in UK general practice: a cluster-randomised factorial trial. Lancet 2004;364:1667-77.

41 Daniels R, Van Rossum HIJ, Beurskens A, Van den Heuvel W, De Witte L. The predictive validity of three self-report screening instruments for identifying frail older people in the community. BMC Public Health 2012;12:69.

42 Pijpers E, Ferreira I, Stehouwer CDA, Nieuwenhuijzen Kruseman AC. The frailty dilemma: review of the predictive accuracy of major frailty scores. Eur J Intern Med 2012;23:118-23.

43 Glasgow RE, Emmons KM. How can we increase translation of research into practice? Types of evidence needed. Annu Rev Public Health 2007;28:413-33.

44 Siegert RJ, Taylor WJ. Theoretical aspects of goal-setting and motivation in rehabilitation. Disabil Rehabil 2004;26:1-8.

45 Parsons JGM, Parsons MJG. The effect of a designated tool on person-centred goal identification and service planning among older people receiving homecare in New Zealand. Health Soc Care Community 2012;20:653-62.
46 Law M, Baptiste S, McColl M, Opzoomer A, Polatajko H, Pollock N. The Canadian Occupational Performance Measure: an outcome measure for occupational therapy. Can J Occup Ther 1990;57:82-7.

47 Kiresuk TJ, Sherman RE. Goal attainment scaling: a general method for evaluating comprehensive community mental health programs. Community Ment Health 1968;1:443-53.

48 Smeulders ESTF, van Haastregt JCM, Ambergen T, Uszko-Lencer NHKM, Janssen-Boyne JJJ, Gorgels APM, et al. Nurse-led self-management group programme for patients with congestive heart failure: randomized controlled trial. J Adv Nurs 2010;66:1487-99.

\section{Accepted: 15 August 2013}

\section{Cite this as: BMJ 2013:347:f5264}

This is an Open Access article distributed in accordance with the Creative Commons Attribution Non Commercial (CC BY-NC 3.0) license, which permits others to distribute, remix, adapt, build upon this work non-commercially, and license their derivative works on different terms, provided the original work is properly cited and the use is non-commercial. See: http://creativecommons.org/licenses/by-nc/3.0/. 


\section{Tables}

Table 1| Baseline characteristics of participants in control group and intervention group. Values are numbers (percentages) unless stated otherwise

\begin{tabular}{lcc} 
Characteristics & Control $(\mathbf{n}=\mathbf{1 5 3})$ & Intervention $(\mathbf{n}=\mathbf{1 9 3})$ \\
Mean (SD) age (years) & $76.80(4.92)$ & $77.49(5.28)$ \\
\hline Female sex & $93(61)$ & $106(55)$ \\
\hline Living alone & $80(52)$ & $90(47)$ \\
\hline Low education & $94(61)$ & $108(56)$ \\
\hline Mean (SD) scores: & $30.58^{*}(10.62)$ & $33.09^{*}(11.52)$ \\
\hline GARS total & $16.54^{*}(5.35)$ & $17.97^{*}(6.14)$ \\
\hline GARS ADL scale & $14.03(5.86)$ & $15.12(5.96)$ \\
\hline GARS IADL scale & $1.90(1.63)$ & $1.63(1.48)$ \\
\hline MSPP-CP-D & $0.46(0.44)$ & $0.36(0.35)$ \\
\hline MSPP-CP-F & $0.73(0.88)$ & 0.610 .84 \\
\hline MSPP-FSP-D & $0.45(0.63)$ & $0.38(0.55)$ \\
\hline MSPP-FSP-F & $12.38(4.72)$ & $13.24(5.39)$ \\
\hline Short FES-I & $6.69(4.35)$ & $6.54(3.77)$ \\
\hline HADS-D & $27.46(6.06)$ & $27.17(6.30)$ \\
\hline SSL-I12 & $6.72^{*}(1.71)$ & $7.13^{*}(1.89)$ \\
\hline GFI & $21.41(4.25)$ & $21.97(4.01)$ \\
\hline PMS & &
\end{tabular}

GARS=Groningen Activity Restriction Scale (range total scale 18-78, range activities of daily living (ADL) scale 11-44, range instrumental ADL (IADL) scale 7-28; higher scores indicate more disability); MSPP=Maastricht Social Participation Profile; MSPP-CP-D=MSPP consumptive participation, diversity score (range 0-7; higher score indicates more diverse consumptive participation); MSPP-CP-F=MSPP consumptive participation, frequency score (range 0-3; higher score indicates more frequent consumptive participation); MSPP-FSP-D=MSPP formal social participation, diversity score (range 0-7; higher score indicates more diverse formal social participation); MSPP-FSP-F=MSSP formal social participation, frequency score (range 0-3; higher score indicates more frequent formal social participation); Short FES-I=Short Falls Efficacy Scale_-International (range 7-28; higher score indicates more fear of falling); HADS-D=Hospital Anxiety and Depression Scale-depression subscale (range 0-21, higher score indicates more depressive); SSL-I12=Social Support List-Interaction version (range 12-48; higher score indicates more social support); GFI=Groningen Frailty Indicator (range 0-15; higher score indicates more severe frailty); PMS=Pearlin Mastery Scale (higher score indicates less own control).

*Significant differences: $\mathrm{P}<0.05$. 
Table 2| Multilevel analyses for differences between control group (CG) and intervention group (IG) for primary outcome measures at 6 , 12 , and 24 months' follow-up $(n=310)$

\begin{tabular}{|c|c|c|c|c|c|c|c|c|c|}
\hline \multirow[b]{3}{*}{ Outcome } & \multicolumn{3}{|c|}{6 months' follow-up } & \multicolumn{3}{|c|}{12 months' follow-up } & \multicolumn{3}{|c|}{24 months' follow-up } \\
\hline & \multicolumn{2}{|c|}{ Mean (SD) } & \multirow{2}{*}{$\begin{array}{c}\text { Mean } \\
\text { difference* } \\
(95 \% \mathrm{Cl}) ; \mathbf{P} \\
\text { value }\end{array}$} & \multicolumn{2}{|c|}{ Mean (SD) } & \multirow{2}{*}{$\begin{array}{c}\text { Mean } \\
\text { difference* } \\
(95 \% \mathrm{Cl}) ; \mathrm{P} \\
\text { value }\end{array}$} & \multicolumn{2}{|c|}{ Mean (SD) } & \multirow{2}{*}{$\begin{array}{c}\text { Mean } \\
\text { difference* } \\
(95 \% \mathrm{Cl}) ; \mathrm{P} \\
\text { value }\end{array}$} \\
\hline & CG & IG & & CG & IG & & CG & IG & \\
\hline GARS & $\begin{array}{c}30.16 \\
(10.07) \\
\end{array}$ & $\begin{array}{c}32.83 \\
(10.98) \\
\end{array}$ & $\begin{array}{c}0.41(-0.80 \text { to } \\
1.62) ; 0.51\end{array}$ & $\begin{array}{c}30.81 \\
(10.29) \\
\end{array}$ & $\begin{array}{c}33.08 \\
(11.34) \\
\end{array}$ & $\begin{array}{c}0.47(-0.81 \text { to } \\
1.76) ; 0.47\end{array}$ & $\begin{array}{c}31.50 \\
(10.92)\end{array}$ & $\begin{array}{c}34.39 \\
(11.58) \\
\end{array}$ & $\begin{array}{c}1.18(-0.35 \text { to } \\
2.71) ; 0.35\end{array}$ \\
\hline $\begin{array}{l}\text { GARS } \\
\text { ADL }\end{array}$ & $16.17(5.13)$ & $17.54(5.82)$ & $\begin{array}{c}0.25(-0.44 \text { to } \\
0.94) ; 0.48\end{array}$ & 16.30 & $17.81(5.90)$ & $\begin{array}{c}0.59(-0.14 \text { to } \\
1.33) ; 0.11\end{array}$ & $16.73(5.73)$ & $18.31(5.82)$ & $\begin{array}{c}0.77(-0.05 \text { to } \\
1.59) ; 0.07\end{array}$ \\
\hline $\begin{array}{l}\text { GARS } \\
\text { IADL }\end{array}$ & $14.00(5.51)$ & $15.29(5.92)$ & $\begin{array}{c}0.17(-0.63 \text { to } \\
0.97) ; 0.67\end{array}$ & $14.51(5.69)$ & $15.28(6.03)$ & $\begin{array}{c}-0.12(-0.93 \text { to } \\
0.68) ; 0.76\end{array}$ & $14.77(5.86)$ & $16.08(6.35)$ & $\begin{array}{c}0.40(-0.54 \text { to } \\
1.34) ; 0.41\end{array}$ \\
\hline
\end{tabular}

GARS=Groningen Activity Restriction Scale (range total scale 18-78; higher scores indicate more disability); GARS ADL=Groningen Activity Restriction Scale-activities of daily living (ADL) subscale (range total scale 11-44; higher scores indicate more disability); GARS IADL=Groningen Activity Restriction Scale-instrumental ADL subscale (range total scale 7-28; higher scores indicate more disability).

*Adjusted for age, sex, education, and significant differences at baseline (frailty and disability). 
Table 3| Multilevel analyses for differences between control group (CG) and intervention group (IG) for secondary outcome measures at 6, 12, and 24 months' follow-up

\begin{tabular}{|c|c|c|c|c|c|c|c|c|c|}
\hline \multirow[b]{3}{*}{ Outcome } & \multicolumn{3}{|c|}{6 months' follow-up } & \multicolumn{3}{|c|}{12 months' follow-up } & \multicolumn{3}{|c|}{24 months' follow-up } \\
\hline & \multicolumn{2}{|c|}{ Mean (SD) } & \multirow{2}{*}{$\begin{array}{c}\text { Mean } \\
\text { difference* } \\
(95 \% \mathrm{CI}) ; \mathrm{P} \\
\text { value }\end{array}$} & \multicolumn{2}{|c|}{ Mean (SD) } & \multirow{2}{*}{$\begin{array}{c}\text { Mean } \\
\text { difference }^{\star} \\
(95 \% \mathrm{Cl}) ; \mathrm{P} \\
\text { value }\end{array}$} & \multicolumn{2}{|c|}{ Mean (SD) } & \multirow{2}{*}{$\begin{array}{c}\text { Mean } \\
\text { difference* }^{*} \\
(95 \% \mathrm{Cl}) ; \mathrm{P} \\
\text { value }\end{array}$} \\
\hline & CG & IG & & CG & IG & & CG & IG & \\
\hline $\begin{array}{l}\text { MSPP-CP-D } \\
(n=310)\end{array}$ & $2.10(1.63)$ & $1.92(1.57)$ & $\begin{array}{c}-0.06(-0.21 \text { to } \\
0.09) ; 0.71\end{array}$ & $2.10(1.64)$ & $1.73(1.45)$ & $\begin{array}{c}-0.22(-0.48 \text { to } \\
0.03) ; 0.09\end{array}$ & $1.94(1.70)$ & $1.61(1.33)$ & $\begin{array}{c}-0.13(-0.43 \text { to } \\
0.16) ; 0.38\end{array}$ \\
\hline $\begin{array}{l}\text { MSPP-CP-F } \\
(n=310)\end{array}$ & $0.46(0.40)$ & $0.40(0.36)$ & $\begin{array}{c}0.00(-0.04 \text { to } \\
0.03) ; 0.96\end{array}$ & $0.45(0.40)$ & $0.35(0.32)$ & $\begin{array}{c}-0.05(-0.11 \text { to } \\
0.01) ; 0.12\end{array}$ & $0.44(0.45)$ & $0.33(0.31)$ & $\begin{array}{c}-0.04(-0.11 \text { to } \\
0.04) ; 0.32\end{array}$ \\
\hline $\begin{array}{l}\text { MSPP-FSP-D } \\
(\mathrm{n}=310)\end{array}$ & $0.69(0.88)$ & $0.64(0.79)$ & $\begin{array}{c}0.03(-0.05 \text { to } \\
0.10) ; 0.73\end{array}$ & $0.73(0.91)$ & $0.60(0.81)$ & $\begin{array}{c}-0.06(-0.14 \text { to } \\
0.02) ; 0.43\end{array}$ & $0.71(0.87)$ & $0.58(0.77)$ & $\begin{array}{c}-0.04(-0.12 \text { to } \\
0.04) ; 0.57\end{array}$ \\
\hline $\begin{array}{l}\text { MSPP-FSP-F } \\
(\mathrm{n}=310)\end{array}$ & $0.41(0.59)$ & $0.39(0.55)$ & $\begin{array}{c}0.03(-0.02 \text { to } \\
0.08) ; 0.52\end{array}$ & $0.43(0.62)$ & $0.35(0.51)$ & $\begin{array}{c}-0.03(-0.08 \text { to } \\
0.01) ; 0.47\end{array}$ & $0.45(0.64)$ & $0.34(0.51)$ & $\begin{array}{c}-0.05(-0.11 \text { to } \\
0.00) ; 0.31\end{array}$ \\
\hline $\begin{array}{l}\text { HADS-D } \\
(n=305)\end{array}$ & $5.82(3.88)$ & $5.72(3.49)$ & $\begin{array}{c}-0.11(-0.80 \text { to } \\
0.58) ; 0.76\end{array}$ & $5.68(3.92)$ & $6.36(4.13)$ & $\begin{array}{c}0.78(0.04 \text { to } \\
1.53) ; 0.04\end{array}$ & $6.10(3.78)$ & $5.97(4.18)$ & $\begin{array}{c}-0.07(-0.90 \text { to } \\
0.77) ; 0.87\end{array}$ \\
\hline $\begin{array}{l}\text { SSL-I12 } \\
(n=312) \\
\end{array}$ & $26.94(5.53)$ & $27.03(6.36)$ & $\begin{array}{c}0.18(-079 \text { to } \\
1.15) ; 0.71\end{array}$ & $27.27(6.54)$ & $27.10(6.09)$ & $\begin{array}{c}-0.12(-1.22 \text { to } \\
0.99) ; 0.84\end{array}$ & $27.35(6.27)$ & $26.76(5.98)$ & $\begin{array}{c}-0.29(-1.37 \text { to } \\
0.79) ; 0.60\end{array}$ \\
\hline $\begin{array}{l}\text { Short FES-I } \\
(\mathrm{n}=306)\end{array}$ & $12.37(4.90)$ & $12.66(5.25)$ & $\begin{array}{c}-0.67(-1.48 \text { to } \\
0.14) ; 0.11\end{array}$ & $12.15(5.24)$ & $13.42(5.43)$ & $\begin{array}{c}0.34(-0.54 \text { to } \\
1.22) ; 0.44\end{array}$ & $12.95(5.29)$ & $13.73(5.75)$ & $\begin{array}{c}-0.04(-1.01 \text { to } \\
0.93) ; 0.94\end{array}$ \\
\hline
\end{tabular}

MSPP =Maastricht Social Participation Profile, MSPP-CP-D=MSPP consumpative participation diversity score (range 0-7; higher score indicates more diverse consumptive participation); MSPP-CP-F=MSPP consumptive participation, frequency score (range 0-3; higher score indicates more frequent consumptive participation); MSPP-FSP-D=MSPP formal social participation, diversity score (range 0-7; higher score indicates more diverse formal social participation); MSPP-FSP-F=MSPP formal social participation, frequency score (range 0-3; higher score indicates more frequent formal social participation); HADS-D=Hospital Anxiety and Depression Scale-depression subscale (range 0-21, higher score indicates more depressive); SSL-I12=Social Support List-Interaction version (range 12-48; higher score indicates more social support); Short FES-I=Short Falls Efficacy Scale-International (range 7-28; higher score indicates more fear of falling).

*Adjusted for age, sex, education, significant differences at baseline (frailty and disability), and baseline status outcome measure. 


\section{Figures}

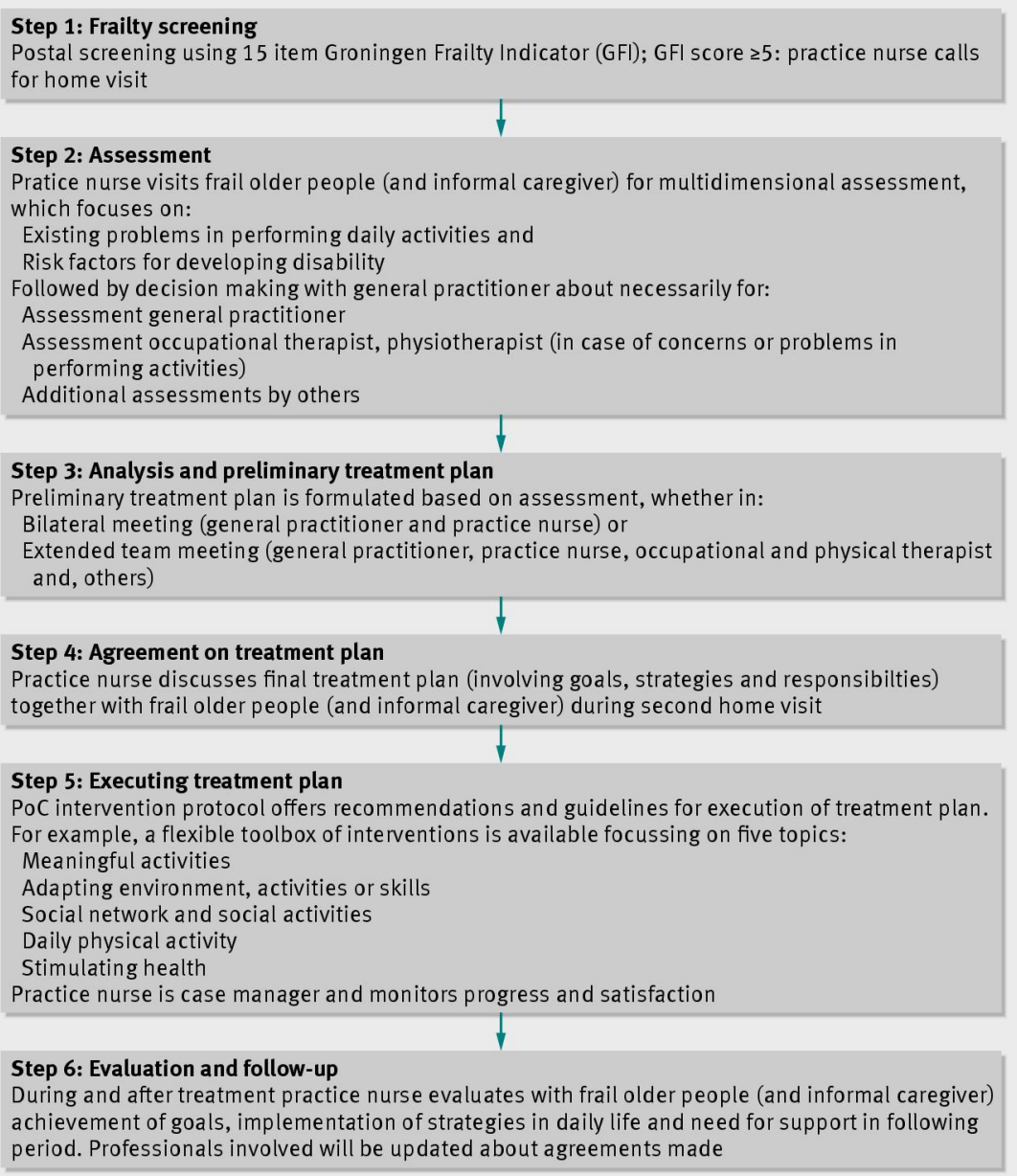

Fig 1 Six steps of Prevention of Care approach 


\begin{tabular}{|c|c|}
\hline \multicolumn{2}{|c|}{ General practices $(n=12)$} \\
\hline\lceil & 7 \\
\hline $\begin{array}{l}\text { Allocated to PoC approach ( } n=6 \text { practices) } \\
\text { Approached }(n=1825) \\
\text { Returned questionnaire }(n=1477,81 \%) \\
\text { Consent }(n=569,39 \%) \\
\text { Screening positive }(n=214,38 \%) \\
\text { Baseline completed/included }(n=193,90 \%) \\
\text { Dropped out before baseline }(n=21) \text { : } \\
\text { Death }(n=1) \\
\text { Admission }(n=0) \\
\text { Health problems }(n=5) \\
\text { Lost interest }(n=6) \\
\text { Other reasons }(n=9)\end{array}$ & $\begin{array}{l}\text { Allocated to care as usual ( } n=6 \text { practices) } \\
\text { Approached ( } n=1673) \\
\text { Returned questionnaire }(n=1313,79 \%) \\
\text { Consent }(n=532,41 \%) \\
\text { Screening positive }(n=179,34 \%) \\
\text { Baseline completed/included }(n=153,85 \%) \\
\text { Dropped out before baseline }(n=26): \\
\text { Death }(n=4) \\
\text { Admission }(n=4) \\
\text { Health problems }(n=6) \\
\text { Lost interest }(n=7) \\
\text { Other reasons }(n=5)\end{array}$ \\
\hline$\downarrow$ & $\downarrow$ \\
\hline $\begin{array}{l}6 \text { month follow-up }(n=171,89 \%) \\
\text { Lost to follow-up }(n=22) \text { : } \\
\text { Death }(n=4) \\
\text { Admission }(n=3) \\
\text { Health problems }(n=5) \\
\text { Lost interest }(n=6) \\
\text { Other reasons }(n=4)\end{array}$ & $\begin{array}{l}6 \text { month follow-up }(n=145,95 \%) \\
\text { Lost to follow-up }(n=8) \text { : } \\
\text { Death }(n=2) \\
\text { Admission }(n=1) \\
\text { Health problems }(n=2) \\
\text { Lost interest }(n=2) \\
\text { Other reasons }(n=1)\end{array}$ \\
\hline$\downarrow$ & $\downarrow$ \\
\hline $\begin{array}{l}12 \text { month follow-up }(n=157,81 \%) \\
\text { Lost to follow-up }(n=14) \text { : } \\
\text { Death }(n=5) \\
\text { Admission }(n=2) \\
\text { Health problems }(n=4) \\
\text { Lost interest }(n=2) \\
\text { Other reasons }(n=1)\end{array}$ & $\begin{array}{l}12 \text { month follow-up }(n=141,92 \%) \\
\text { Lost to follow-up }(n=4) \text { : } \\
\text { Death }(n=1) \\
\text { Admission }(n=1) \\
\text { Health problems }(n=1) \\
\text { Lost interest }(n=1) \\
\text { Other reasons }(n=0)\end{array}$ \\
\hline$\downarrow$ & $\downarrow$ \\
\hline $\begin{array}{l}24 \text { month follow-up }(n=143,74 \%) \\
\text { Lost to follow-up }(n=14) \text { : } \\
\text { Death }(n=6) \\
\text { Admission }(n=3) \\
\text { Health problems }(n=3) \\
\text { Lost interest }(n=0) \\
\text { Other reasons }(n=2)\end{array}$ & $\begin{array}{l}24 \text { month follow-up }(n=127,83 \%) \\
\text { Lost to follow-up }(n=14) \text { : } \\
\text { Death }(n=7) \\
\text { Admission }(n=3) \\
\text { Health problems }(n=1) \\
\text { Lost interest }(n=3) \\
\text { Other reasons }(n=0)\end{array}$ \\
\hline
\end{tabular}

Fig 2 Flow of participants through trial. $\mathrm{PoC}=$ Prevention of Care 